
TO VEHICLE DESIGN

Janet Braun, Western Washington University 


\title{
Reflective Journaling on a Systems Approach to Vehicle Design
}

\begin{abstract}
Soft skills, such as the ability to function effectively on teams, to communicate effectively, to engage in lifelong learning, and to understand professional, ethical and social responsibilities, are required outcomes for ABET accredited Engineering Technology Programs. Input from industry advisory councils and feedback from employed alumni agree that these skills are crucial, regardless of the industry or type of work. The author, being personally motivated from nearly two decades of industry experience in engineering management and leadership roles, has attempted to help students develop these important skills in one upper division course in the context of using a systems approach to vehicle design.

A systems approach to vehicle design is essential in a competitive environment, especially in times of financial strain. The complexity of systems on modern vehicles requires the concurrent involvement of multiple disciplines in order to shorten development cycles and reduce development costs. This is possible if development is done in a common framework providing a common communication platform for all disciplines. One such platform is MATLAB/Simulink software developed by The Mathworks. Industry has widely adopted such platforms for product design, simulation and testing, driving the need for engineering educators to incorporate this into engineering curriculums.

This paper outlines the parallel processes of developing of soft skills while learning a systems approach to vehicle design by using MATLAB/Simulink. Coursework which was developed in part by Rose-Hulman Institute of Technology and The Mathworks provided the basis for the model based system design content of the course. A reflective journal was incorporated to foster a deeper dimension of self-learning, requiring students to step back and analyze the implications of a systems approach to vehicle design as well as the impact of this approach on the wider organization as well as society. Journal prompts were assigned to stimulate thoughtful reflection on the role of the student in the collaborative approach to this process through prompting for evidence of specific behaviors, specifically those generally identified as important communication and teamwork skills. The journals as well as a post-course survey provide evidence of students developing a systems approach along with the soft skills necessary for success in a collaborative environment
\end{abstract}




\section{Background}

In the context of an emissions control course, model-based systems design (MBSD) was presented as a pertinent industry tool for modeling automotive systems which often require careful balancing of trade-offs to minimize factors such as cost, emissions, and fuel consumption while maximizing performance and customer acceptance. This context provided a plethora of interactions that must be considered holistically in order to design the best possible system in the shortest amount of time. The structure of the MBSD component of this course was developed in part by Rose-Hulman Institute of Technology and The Mathworks through the Model-BasedSystems Design Center ${ }^{1}$ and provided the students the opportunity to learn the approach while modeling a hybrid vehicle. The software used was MATLAB/Simulink from The Mathworks.

Attempting to incorporate the parallel processes of developing soft skills while learning a systems approach to vehicle design resulted in a course which exercised nearly all of the capabilities outlined in Criterion 3 of the ABET-TAC 2011-2012 Criteria for Accrediting Engineering Technology Programs, listed below ${ }^{2}$. The technical nature of the course and the MBSD tool provided experience with $a, b, d$ and $f$ while the reflective exercises in the course (pre-course essay, reflective journal, and post-course reflection) developed e, $\mathrm{g}, \mathrm{i}$ and $\mathrm{j}$ capabilities.

a. an ability to select and apply the knowledge, techniques, skills, and modern tools of the discipline to broadly-defined engineering technology activities;

b. an ability to select and apply a knowledge of mathematics, science, engineering, and technology to engineering technology problems that require the application of principles and applied procedures or methodologies;

c. an ability to conduct standard tests and measurements; to conduct, analyze, and interpret experiments; and to apply experimental results to improve processes;

d. an ability to design systems, components, or processes for broadly-defined engineering technology problems appropriate to program educational objectives;

e. an ability to function effectively as a member or leader on a technical team;

f. an ability to identify, analyze, and solve broadly-defined engineering technology problems; g. an ability to apply written, oral, and graphical communication in both technical and nontechnical environments; and an ability to identify and use appropriate technical literature;

$h$. an understanding of the need for and an ability to engage in self-directed continuing professional development;

i. an understanding of and a commitment to address professional and ethical responsibilities including a respect for diversity;

j. a knowledge of the impact of engineering technology solutions in a societal and global context; and k. a commitment to quality, timeliness, and continuous improvement.

The reflective exercises incorporated in this course provided the primary means for developing the soft skills required by ABET and desired by engineering graduates. A study outlined by Palazolo, et. al, identified that students felt they lacked sufficient leadership/management skills and overwhelmingly desired to develop these skills, more than any other (including technical and analytic skills), before graduating ${ }^{3}$. Reflective practice was employed successfully by Martinazzi, et. al in an engineering technology program, to help students develop leadership skills ${ }^{4}$. That course was different, however, in that the subject of the course was Leadership. This course, as outlined in this paper, attempted to develop these traits in the context of a simulated real world industry MBSD project focused on automotive emission control. 


\section{Methods}

This mixed methods research was undertaken to determine if the reflective exercises employed during one term of this course along with MBSD were effective in furthering students' development of the following course outcomes:

1. Ability to function well on teams

2. Ability to communicate effectively

3. Understanding of different, often conflicting perspectives and the need to carefully balance trade-offs when making decisions

4. Understanding of professional, ethical and social responsibilities

The reflective exercises employed began with a pre-course reflection essay and continued through the 10 week term with periodic reflective journaling assignments. Details on these exercises can be found in the following sections. Parallel to this, teams were formed about one third of the way into the course. At this point, students were encouraged to work through class exercises with their teams and to turn to their teammates for questions and for help in solving problems. This was intended to stimulate collaboration and teambuilding prior to the team project which was initiated about two thirds of the way through the course, from which point on the teams worked completely independently.

The effectiveness of these tools in achieving the course outcomes was assessed qualitatively through post-course reflections, and quantitatively through survey questions to which the students were asked to respond $1=$ not at all, $2=$ slightly, $3=$ somewhat, $4=$ between somewhat and absolutely, and $5=$ absolutely.

Further quantitative data were gathered using a teamwork assessment tool called The Comprehensive Assessment for Team-Member Effectiveness (CATME) ${ }^{8}$ which was developed through support from the National Science Foundation and is available for instructional use in educational settings at no charge. CATME is a web-based survey found at www.catme.org that gathers data on team-member effectiveness in five areas: contribution, interaction, keeping the team on track, expectation of quality, and relevant skills and abilities. The output provides the instructor with each member's effectiveness on a behaviorally anchored rating scale of 1-5, which describes behaviors that are typical of various levels of performance in each of the five areas.

As data were collected during one term on a class of only 10 students, the extensive quantitative analysis was not conducted. The small class size did, however, allow for the use of the reflective exercises which would have been burdensome to review for a larger class.

\section{Reflective Exercises}

Pre-course Reflections

The very first day of class, students were asked to reflect and write an essay on leadership and teamwork. This essay was designed to have students assess their current understanding of various team roles along with their strengths and weaknesses in each of the roles. Students were asked to address each of the following questions in the essay. 
- How do you define each of the roles of Leader, Follower and Team Player? What are the desirable skills, qualities, and attributes of each?

- Reflect on yourself as a Leader, a Follower, and a Team Player. What assets do you bring to each role? What weaknesses?

- What have others said about you in terms of these roles? What evidence has their feedback provided as to their perceptions of you in these roles?

This provided the starting point for their self-reflection, an activity that was repeated several times during the course through a reflective journal.

\section{Reflective Journaling}

In order to ease apprehension about grading on the reflective journal, expectations were established and communicated to the students both verbally and in writing at the beginning of the course. Expectations were modeled after Pavlovich, et. al who assigned a letter grade based on the depth of the reflection. A mere description earned a $\mathrm{C}$ grade, while including analysis, meaning and eventually action earned successively higher grades. ${ }^{5}$ To help students understand how to reflect more deeply, the three level reflective learning focus as defined by Hedberg was presented. This model provides definitions and descriptions to differentiate between subject, personal and critical reflective learning. ${ }^{6}$

Learning to develop reflective learning skills was part of the challenge of this course for the students. Journal assignments, or prompts, were assigned to stimulate reflection and to encourage students to think critically about the topic. The assignments, which aligned with lecture topics and MBSD lab activities, are listed below with a description that may help readers of this paper understand the pertinence of the assignment.

\section{Table 1 - Reflective Journaling Assignments}

\begin{tabular}{|l|l|}
\hline Journal Assignment & Description \\
\hline $\begin{array}{l}\text { Reflect on the lecture "The Air We Breathe" in terms of } \\
\text { subjective, personal and critical reflective learning. }\end{array}$ & $\begin{array}{l}\text { After providing an introduction to the three types of } \\
\text { reflective learning provided by Hedberg } \\
\text { personal, and critical, students are asked to demonstrate } \\
\text { their understanding by reflecting on the day's lecture } \\
\text { content in terms of each. }\end{array}$ \\
\hline $\begin{array}{l}\text { This week reflect on trade-offs. In automotive design, } \\
\text { we often have to choose solutions that may not be } \\
\text { optimal from an engineering perspective, but may be } \\
\text { necessary when considering the larger picture. In class } \\
\text { we've talked about trade-offs in emissions vs. fuel } \\
\text { economy, conditions for thermal oxidation and catalytic } \\
\text { oxidation, etc. In a design team, engineering will make } \\
\text { trade-offs in favor or marketing, production, and } \\
\text { service/aftermarket considerations (to name a few!). } \\
\text { Reflect on your own experience dealing with trade-offs } \\
\text { in a broader context and how you handled them. }\end{array}$ & $\begin{array}{l}\text { The need to sub-optimize in order to satisfy opposing } \\
\text { goals is a common theme repeated throughout this } \\
\text { course. There is a teamwork emphasis to this } \\
\text { assignment in recognizing trade-offs required due to the } \\
\text { sometimes opposing goals of the various disciplines } \\
\text { involved in a cross-functional team. Students are asked } \\
\text { to reflect on this to expose how they deal with trade-offs } \\
\text { in their personal life with the intent that they will gain } \\
\text { insight into dealing with trade-offs in their career. }\end{array}$ \\
\hline $\begin{array}{l}\text { How can MBSD improve the design process? How has } \\
\text { learning MBSD changed the way you tackle a problem } \\
\text { (any kind of problem)? }\end{array}$ & $\begin{array}{l}\text { Students are asked to recognize the benefits of MBSD in } \\
\text { the context of automotive system design. They are also } \\
\text { asked for evidence of learning by prompting for } \\
\text { evidence of applying the principles to problem solving } \\
\text { outside of the MBSD process. }\end{array}$ \\
\hline \begin{tabular}{l} 
You can help the environment while working for an oil \\
\hline
\end{tabular}
\end{tabular}


department, from an oil refinery and from a Class 8 truck manufacturer, each discussed some of the tradeoffs associated with emission control. What kind of impact does this have on you? Did this open your eyes to anything you hadn't considered before? Has anything changed for you?

Thoughts on teamwork: Reflect on these excerpts in terms of your own experience in our class and in working in your teams on model-based systems design.

- Solutions to adaptive challenges reside not in the executive suite but in the collective intelligence of employees at all levels.

- No one learns anything without being open to contrasting points of view.

- Held in debate, people can learn their way to collective solutions when they understand one another's assumptions.

- People have to discover the value of consulting with one another and using one another as resources in the problem-solving process.

- Letting people take the initiative in defining and solving problems means that management needs to learn to support rather than control. Workers, for their part, need to learn to take responsibility. ${ }^{7}$ refiner, ensuring compliance is costly and not necessarily feasible, and even a large truck experiences packaging challenges with emissions control equipment. These are just some of the perspectives provided by industry guest lecturers that the students had not previously considered. Balancing trade-offs is again the theme.

These excerpts were chosen to emphasize the necessity for teamwork in the workplace and the classroom and to prompt for evidence where students disagreed with teammates, learned to appreciate each others' views and to depend on each others' help in completing the team project. The last excerpt was included for the satisfaction of the instructor (and author of this paper) to encourage students to take control of their learning instead of relying solely on the instructor to pave the way.

\section{Findings}

\section{Post-Course Reflections and Survey}

The finale of the reflective exercises was an online survey of ten questions, nine of which required a numerical rating of the applicability of a statement, with one being "not at all" and five being "absolutely". Each of the nine quantifiable questions also asked for specific evidence to support the rating. The questions can be found in Table 2. The average rating for each of these nine quantifiable questions is shown in Figure 1. Details on the six statements that the students rated most highly follows, along with Figures 2 thru 7.

\section{Table 2 - Post-Course Reflective Questions}

1. How valuable is a systems based approach to a vehicle designer in helping to balance trade-offs and opposing goals?

2. Did you gain any major insights into your own learning process in this course?

3. To what degree has learning model based systems design this quarter influenced your ability and/or willingness to collaborate?

4. Did you learn anything about yourself through self-reflection that prompted you to change your behavior in terms of collaboration/teamwork or communication? 
5. Did you receive any feedback from others that prompted you to change your behavior in terms of collaboration/teamwork or communication?

6. Have your collaboritive/teamwork skills improved?

7. Have your communication skills improved?

8. Have you developed a broader perspective?

9. Has this course helped you better understand your professional, ethical and social responsibilities?

10. What knowledge, ideas or issues will you take with you as you leave this course?

\section{Post-Course Reflection Responses}

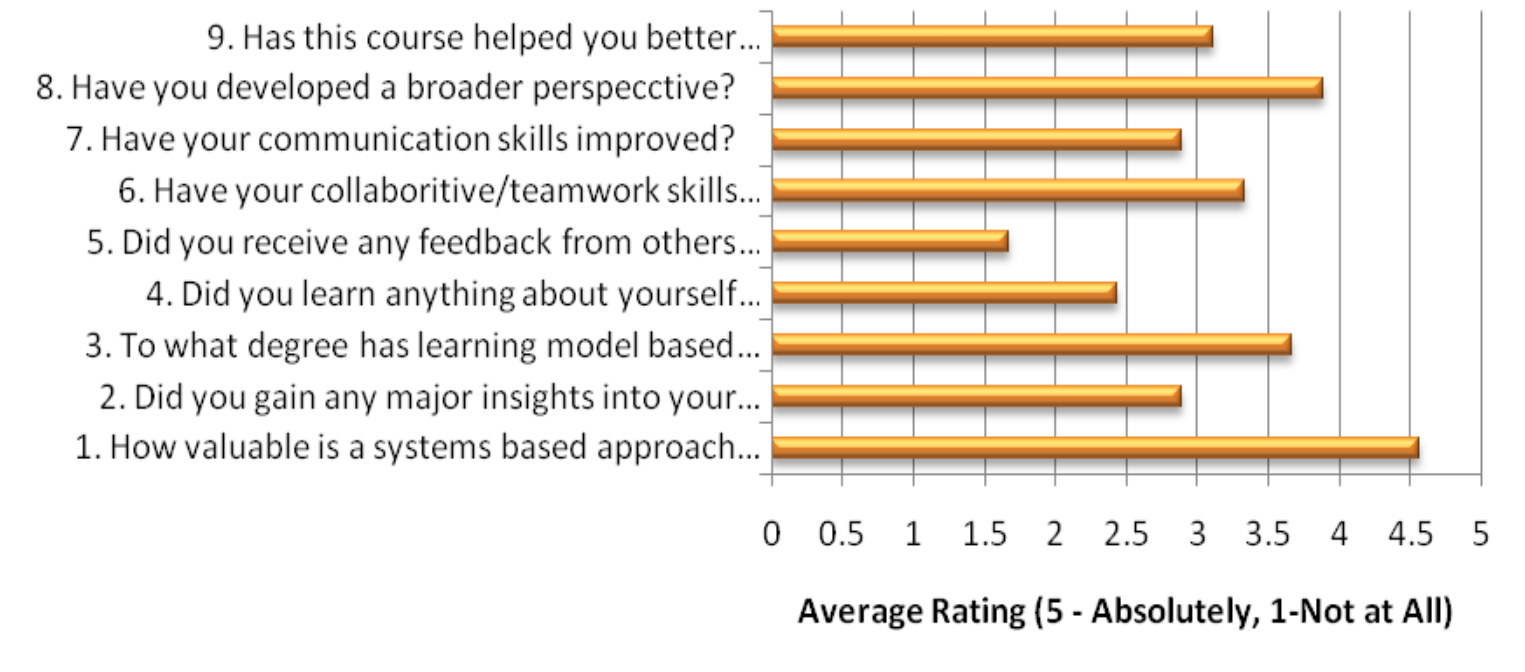

\section{Figure 1 - Post-Course Reflection Average Ratings}

\section{Question 1 - How valuable is a systems based approach to a vehicle designer in helping to balance trade-offs and opposing goals?}

As Figures 1 and 2 show, the students overwhelmingly agreed that MBSD is a very valuable tool in balancing trade-offs and opposing goals. The average rating was 4.56. The theme of the evidence provided was much the same, noting the interaction of systems "it helped me understand how different systems work together and how changes in one system effect other systems" and the comparison of systems "it allows us to change parameters and see the outcomes. It is a great tool to help compare results". Comments to Question 10 also support the value of this tool as one student recognized that"modeling things in Simulink/MATLAB will allow me to not just better understand their complexity, but also, better understand my basic assumptions". 


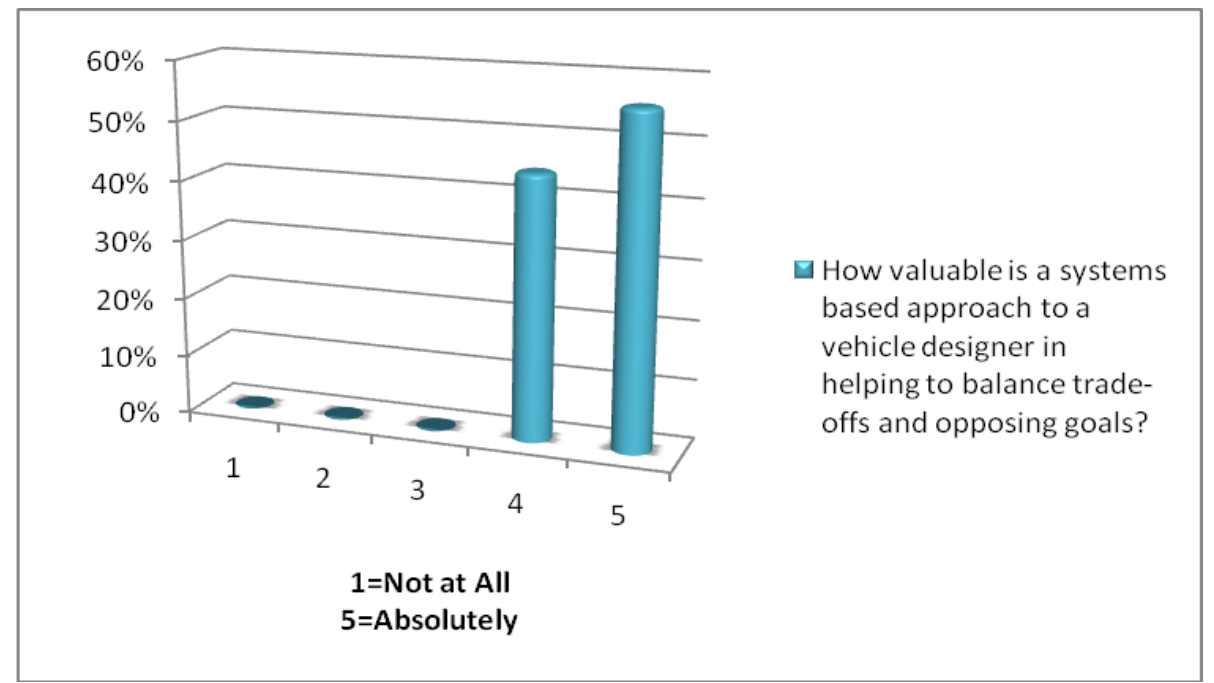

Figure 2 - Rating Details for Question 1

\section{Question 3 - To what degree has learning model based systems design this quarter influenced your ability and/or willingness to collaborate?}

Even though the average rating for this questions was 3.67, just over the midpoint, the comments provided by the students indicate that MBSD fostered a great deal of collaboration. Some students chose a 2 or 3 rating simply because they felt they were already quite willing to collaborate. This appears to be an issue with the wording of the question and will be modified for subsequent surveys.

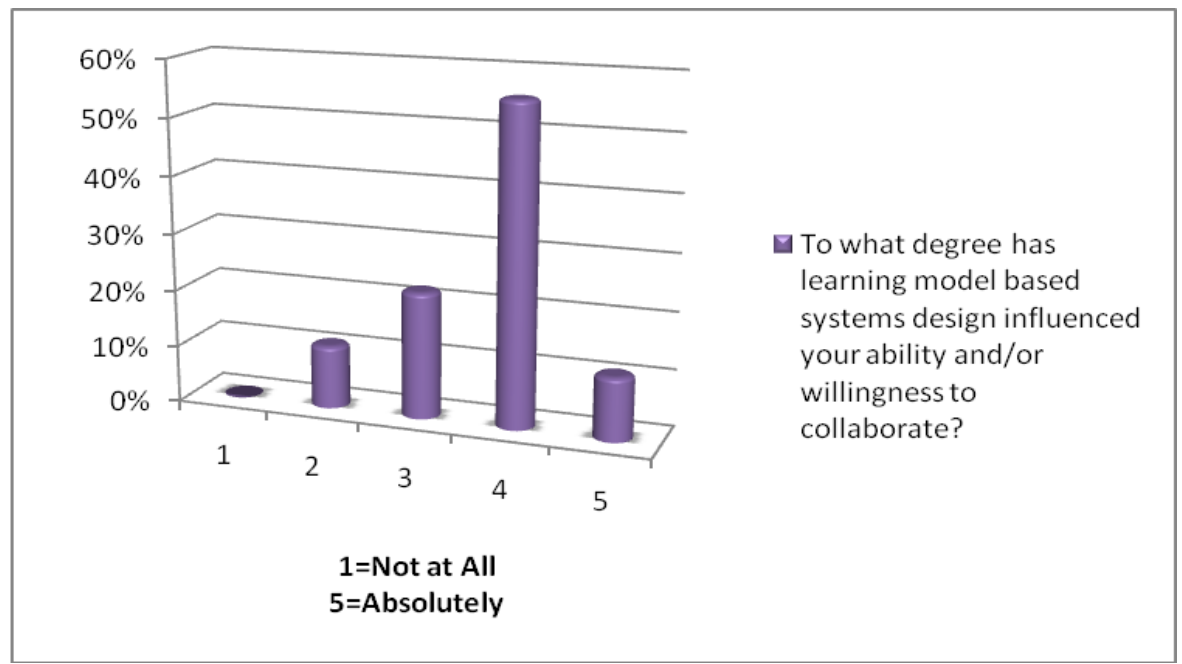

Figure 3 - Rating Details for Question 3

One big factor in the high degree of collaboration was the difficulty of learning a new tool and the complexity of the systems modeled. As one student pointed out "I realized that the only way I was going to make it through the quarter was if I started asking my teammates for help". Another student adds that "MBSD has definitely forced me to collaborate with my team. This system can be very difficult to de-bug so having the help of others is very useful". 
On the opposite end of the spectrum were the students who were held back to the pace of their team. While at first frustrated by this, one student wrote "ultimately I learned more from being able to help others, since teaching is the last step to really learning and understanding the material that you are working with". Also, there was the student who was quite used to working in groups, with each person on different parts, but had difficulty when collaborating on one main part. He stated "I definitely learned a bit more about how to work as a team on a single system...I got some practice with this in this class and on our project and I think I'll be better at it in the future".

\section{Question 6 - Have your collaboritive/teamwork skills improved?}

Approximately half the students described themselves as having well developed collaborative/teamwork skills, therefore this question received an average rating of 3.33. The students in the other half all indicated they had improved. One student stated "I am more open to using teamwork and collaboration after taking this course", indicating a previous tendency to do all the work alone instead of putting up with team members. Another points out that this course "helped me in getting a bit more familiar with myself and how I work in a team" demonstrating the type of increased self-awareness this course was designed to develop.

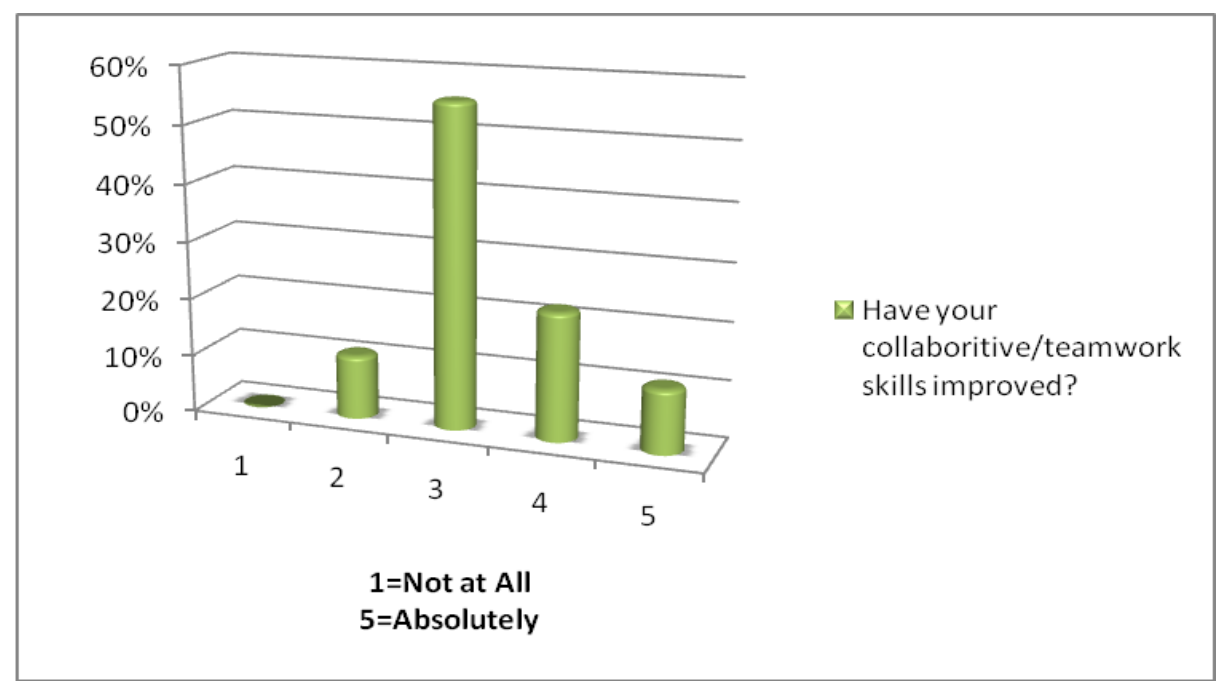

Figure 4 - Rating Details for Question 6

\section{Question 7 - Have your communication skills improved?}

Overall, scoring only 2.89 , there was not much evidence that communication skills improved during this course. Some students reiterated the "practice makes perfect" mantra, but there were very few meaningful comments with the exception of one: "I definitely improved in asking questions. That's not something I've ever been very good at or very comfortable doing". This is perhaps better evidence of a willingness to collaborate due to the increased confidence gained to ask questions. 


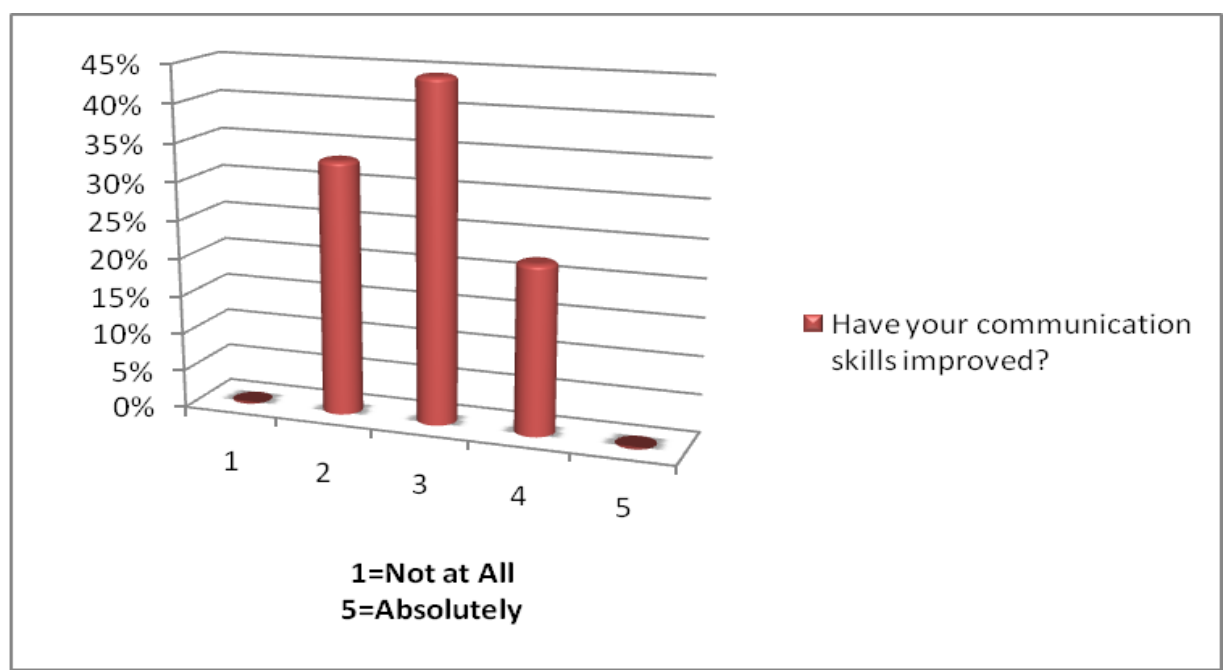

Figure 5 - Rating Details for Question 7

\section{Question 8 - Have you developed a broader perspective?}

A somewhat broader perspective was gained by all students, as evidenced by the 3.89 average rating on this question. As the instructor with 17 years of industry experience, the author breathes a sigh of relief, knowing that these students are now just a little bit better prepared to find success in industry. While some students answered this question with strict reference to MBSD, the intent was for the student to consider the overall course content, including the emissions control portion. About MBSD, one student stated that "at the start I didn't really understand how or why we were designing our system in this way but about halfway through I began to realize how useful the program really is and that it really does make sense to design our systems this way". This revelation was shared by others as well.

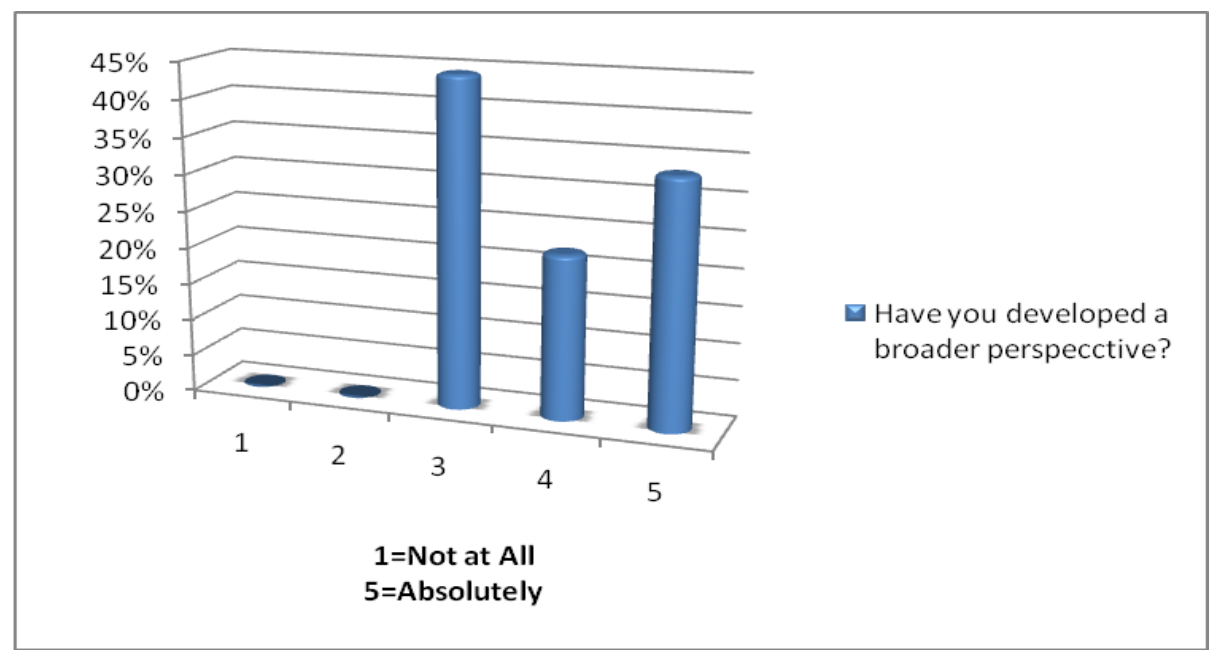

Figure 6 - Rating Details for Question 8

In the broader context, several of the students developed a broader perspective about what goes on in industry. Referring to a guest lecturer from an oil refinery, typical comments were "this helped me to understand the oil-to-fuel side of the business and why some things are the way that 
they are" and comparing to what they'd learned in an alternative fuels class, "it was refreshing to hear the viewpoint of one of the 'evil companies' about what they are doing to be as green as possible and what they think about all the hearsay". This provides clear evidence that the intent of broadening students' perspectives was accomplished in this course.

\section{Question 9 - Has this course helped you better understand your professional, ethical and social responsibilities?}

Despite learning about emission control regulations and the design strategies employed to reduce emissions, some students were uncertain whether they gained a better understanding of their professional, ethical and social responsibilities. Since this was the second to last reflective question, the author chalks this up to last-day-of-class attention deficit disorder. Most students gained at least a somewhat better understanding, but one student summed it up perfectly:

"The class helped me realize why emission standards are so important and why it is our responsibility to reduce them. But at the same time the class made me question some ethics for example the political side of emissions controls limiting large companies rather than leisure vehicle emissions and other countries refusing to implement any emissions standards."

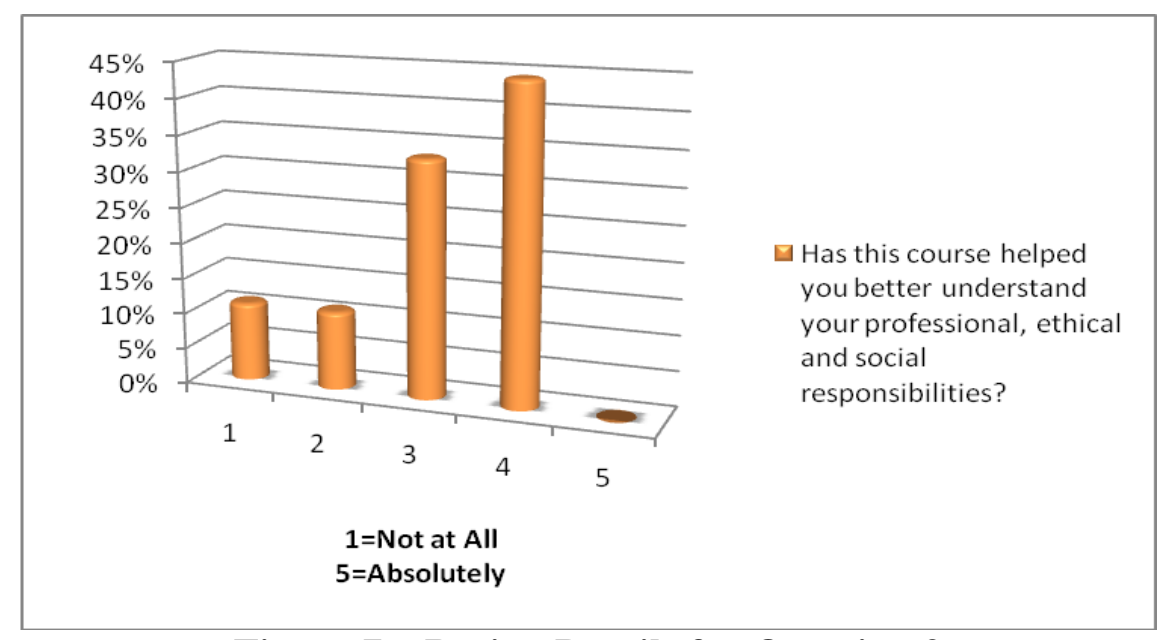

Figure 7 - Rating Details for Question 9

\section{Team Peer Assessment}

Summary data for the CATME teamwork assessment tool are shown in Table 3. The rating scale ranges from one being the lowest to five being the highest. No exceptional conditions (such as manipulators, over or under confident, conflict, etc.) were identified by the assessment tool as being present within teams in this course, and all team members were rated above average in effectiveness in all five categories. This provides evidence that "the ability to function effectively on teams" outcome was achieved in this class. 
Table 3 - Summary of CATME Teamwork Assessment

\begin{tabular}{|c|c|c|c|c|c|c|}
\hline & Team ID & $\begin{array}{c}\text { Contribution to } \\
\text { Team }\end{array}$ & $\begin{array}{c}\text { Interaction } \\
\text { w/Teammates }\end{array}$ & $\begin{array}{c}\text { Keeping Team } \\
\text { on Track }\end{array}$ & $\begin{array}{c}\text { Having Related } \\
\text { Knowledge, Skills, } \\
\text { and Abilities }\end{array}$ \\
\hline Student 1 & 1 & 4 & 4 & 3.5 & 3.8 & 3.5 \\
\hline Student 2 & 1 & 4 & 4 & 3.8 & 4 & 3.5 \\
\hline Student 3 & 1 & 4.2 & 4 & 3.8 & 4 & 3.5 \\
\hline Student 4 & 1 & 4.8 & 4 & 3.8 & 4 & 3.8 \\
\hline Student 5 & 2 & 4.3 & 5 & 4.3 & 4.3 & 4 \\
\hline Student 6 & 2 & 3.7 & 4.3 & 4 & 4.3 & 4 \\
\hline Student 7 & 2 & 4.7 & 4.7 & 4.3 & 4.3 & 4.3 \\
\hline Student 8 & 3 & 5 & 5 & 5 & 5 & 5 \\
\hline Student 9 & 3 & 5 & 5 & 5 & 5 & 5 \\
\hline Student 10 & 3 & 5 & 5 & 5 & 5 & 5 \\
\hline
\end{tabular}

\section{Discussion and Conclusion}

Overall, the author is satisfied that the use of reflective journaling in fostering the development of soft skills such as collaboration and teamwork. Responses to survey questions 3 and 6 indicate that $89 \%$ of students improved their willingness and ability to collaborate during this course. Even though they may have been willing and able to do so at the beginning of the term, using the MBSD tool forced a higher level of collaboration. The CATME teamwork assessment indicates that each of the teams was able to function effectively at this higher level of collaboration, reinforcing the survey responses.

Furthermore, the results of the survey indicate that $64 \%$ of students felt their communication skills may have improved at least somewhat, and at the very least, they had the opportunity to practice them a bit more. Again, the CATME teamwork assessment does not indicate anything to the contrary and the teams were shown to work effectively, and this requires communication.

Most notably, it appears reflective journaling did a stellar job of broadening the students' perspectives, which the author believes to be a crucial part of preparing students for industry careers. Survey question 1 , which deals with balancing trade-offs, and question 8 , which asks "have you developed a broader perspective?", provide the most compelling data in the study, with average responses of 4.56 and 3.89 respectively, and $100 \%$ of students responding with at least a 3 (somewhat). In contrast to the questions about communication and collaboration, where the students were less likely to credit this course with providing any improvement in those areas, students clearly recognized a need to balance trade-offs, underscoring the importance of developing a broader perspective. This demonstrated broadening of perspectives provides a real basis for successful collaboration and teamwork in the future. 


\section{References}

1. Herniter, M.E., Chambers, Z., Callanan, E. and Prabhu, S.M., "Combining Passion with Fundamentals Applying Model-Based Design to Eduction”, Society of Automotive Engineers World Congress, 2008.

2. http://www.abet.org/Linked Documents-UPDATE/Program Docs/abet-tac-criteria-2011-2012.pdf

3. Palazolo, P., Camp, C., Lambert, A., Lambert, N., and Dennis, N., "Changing the Paradigm of Power in the Classroom to Teach, Promote, and Evaluate Leadership Training Within and Existing Civil Engineering Curriculum", Proceedings of the American Society for Engineering Education Annual Conference, 2004.

4. Martinazzi, R., Rose, A.T., and Sample, J., "Leadership 101 Developing the Leader in Engineering and Engineering Technology Students", Proceedings of the American Society for Engineering Education Annual Conference, 2004.

5. Pavlovich, K., Collins, E. and Jones, G., 'Developing Students' Skills in Reflective Practice: Design and Assessment", Journal of Management Education, Vol. 33 No. 1, February 2009.

6. Hedberg, P.R. "Learning Through Reflective Classroom Practice: Applications to Educate the Reflective Manager", Journal of Management Education, Vol. 33 No. 1, February 2009.

7. Heifetz, R.A. and Laurie, D.L., "The Work of Leadership”, Harvard Business Review Breakthrough Leadership, December 2001.

8. Loughry, M.L., M.W. Ohland, and D.D. Moore. "Development of a Theory-Based Assessment of Team Member Effectiveness," Educational and Psychological Measurement, 6 2007; vol. 67: pp. 505-524. 